premiums, but others (particularly in NI) concerned at potential surveillance.

Conclusions GDL may have mixed results for reducing road injury in novice drivers, given much risky driving in rural (high risk) areas is 'outside the system', and may be increased by further legislation. However, participants were universally disapproving of one risk (drink driving) suggesting that attitudes to other risks may change as a result of GDL implementation. Evaluation of GDL will need to assess impact on population as well as licensed young driver injury rates to take into account possible reductions in access to cars and shifts towards more vulnerable modes.

\section{AMBULANCE CRASH IN THAILAND}

Anuchar Sethasathien, Teera Sirisamutr, Porntip Wachiradilok, Suchart Dairoop, Sirichai Nimma. National Institute for Emergency Medicine 1669, Thailand

\subsection{6/injuryprev-2016-042156.529}

Background The pre-hospital care providers in Thailand are always challenged by the task difficulty in working with limited resources and spaces, as well as the high risk of encountering traffic accidents. This study aims to elaborate situation and analyse the causes and factors of the ambulance crash in Thailand.

Methods This was a retrospective analysis of all fatal ambulance crash on Thailand public roadways in 2014, from the secondary data in three main sources, including the database of Information Technology for Emergency Medical System (ITEMS), the records of surveillance ambulance accident of EMS from January to December 2014, and the report of ambulance accident investigation collected from the local network in 2014, using the Haddon's matrix approach. The study was conducted from January to March 2015. The results are presented using descriptive statistics Results According to the ambulance accident surveillance data, 61 ambulance accidents occurred in 2014, resulting in 130 injured victims and 19 deaths. The number of accidents is more concentrated during June to August (25 times). The accident rate is 0.05 with the mortality rate of 0.02 per 1,000 operations. Factors related to accident and safeness of the ambulance could be concluded into human factors, vehicle and equipment factors, and road environment factors. Human factors include lack of ambulance driving training, unfastened seat belts, and high speed driving exceeding $90 \mathrm{~km} / \mathrm{hr}$. Unregistered ambulance and missing GPS installation contribute to the lack of vehicle standard. The disparity in each local road environment such as speed curve, crowded site, and missing directive signs lead to higher risk of accident.

Conclusions The proportion between the numbers of ambulances to the Thai population had been declining over the past years. However, accidents caused from the above three factors were still prevalent. Therefore, it is necessary for the related organisations to implement new policies and take actions towards preventing future ambulance accidents.

\section{ROAD CRASHES IN METRO MANILA: OVERVIEW OF ROAD SAFETY}

Sophia Francesca DP Lu. College of Arts and Sciences, University of the Philippines Manila

10.1136/injuryprev-2016-042156.530
Background Road crashes is one of the highest cause of morbidity and fatality in the Philippines.

The study tried to look into the trends of fatal and non-fatal injuries due to road crashes in Metro Manila Philippines, including all other relevant factors such as damage to property, number of registered cars, and time of accident.

Methods The study looked at all raw data and databases coming from all agencies that generate traffic and road safety monitoring and evaluation. These are the Metro manila Development Authority, land Transportation Office, Philippine National Police Road Board, Department of Transportation, and Communication. Several literature reviews were also done.

Results Fatal accidents due to road crashes was investigated from 2005 to 2014. In all the years, there was a minimum of 204 fatalities which was in 2012, and the year 2014 registered the highest at 418 deaths. This data is only for Metro Manila which is the capital of the Philippines. Non-fatal accidents was highest too in 2014 registering at 16,665 cases. Damage to property also peaked in 2014 at 73,175 cases. Most frequent accidents occurred between $10-11 \mathrm{am}$, and $2-3 \mathrm{pm}$. Over the past 10 years, the number of road crashes in the Philippines has been steadily increasing, except for a slight dip for the year 2012. The number of registered cars has also experienced a steady increase. This increase has led to the congestion of roads in Metro Manila, and more risk to road crashes. This is the first ever data on trending of road crashes in the Philippines for a period of 10 years.

Conclusions The data showed that there is an alarming rate of road crashes which calls for road safety programs and policies for driver and public safety in the Philippines.

\section{PLACE OF OCCURRENCE OF TRAFFIC INJURY - CAN WE COMBINE PRE- AND HOSPITAL DATA TO GET LOCATION?}

1,2Frederik Borup Danielsson, ${ }^{3}$ Søren Mikkelsen, ${ }^{1}$ Jens Lauritsen. ${ }^{1}$ Accident Analysis Group (UAG) the Department of Orthopaedic Surgery, Odense University Hospital (OUH), Denmark and Institute of Clinical Medicine, Southern Denmark University; ${ }^{2}$ The Department of Orthopaedic Surgery, SLB Kolding, a Part of Hospital Lillebaelt, Denmark; ${ }^{3}$ Mobile Emergency Care Unit, Department of Anaesthesiology and Intensive Care Medicine, Odense University Hospital, Denmark

\subsection{6/injuryprev-2016-042156.531}

Background It is cumbersome to ask patients for location of occurrence and irrelevant to the treatment upon arrival at hospitals. Since data on location of occurrence are found in ambulances and pre-hospital mobile emergency care units (MECU) information could easily be recorded. It is therefore of interest to explore the potential and possible biases of combining hospital- and pre-hospital data on traffic injury as an alternative to lengthy interviews once patients arrive at the hospital. The specific aim of this study was to assess complement and combined proportions of patients known from ambulances, MECU and trauma registries.

Methods Any patient record documented as "acute traffic injury" in the primary geographic catchment area of Kolding Hospital (level 2 trauma) and Odense University Hospital (level 1 trauma) in Denmark occurring in 2013 was included if identified in at least one of the three registries(hospital trauma, MECU, Ambulance Service). Records were merged on civil registration number and date of injury. Transfers between hospitals were excluded. No other service or hospitals provide service in the area.

Results Primary data consisted of 8895 records (patients) from the ambulance service, 669 from the medical emergency care unit and 564 from the trauma registries (excluding transfers). By 